They are more than other groups of workers loyal to tax evasion by citizens; more often tend to ignore the formalization of employment, thereby expressing readiness to work in the shadow environment. Such a state of affairs may indicate an imbalance in the interests of small businesses, including self-employed citizens, and the state, as well as the presence of signs of the lack of adequate legal regulation of this activity.

Keywords: informal employment, legal culture, legal awareness, legal values, legal behavior, entrepreneurship, labor market, self-employed citizens

БАРАНОВСКИЙ Максим Витальевич - кандидат социологических наук, докторант Военного университета Министерства обороны РФ (123001, Россия, г. Москва, ул. Большая Садовая, 14; m.baranovskj@gmail.com)

\title{
СОВРЕМЕННЫЕ ПРАКТИКИ СОЦИОЛОГИЧЕСКОГО ИЗУЧЕНИЯ ФЕНОМЕНА ДОВЕРИЯ
}

Аннотация. В статье предлагается обзор основных современных практик социологического исследования доверия. Автор приводит собственную классификацию доверия как социального явления по различным основаниям. На основе анализа тематики и содержания научных публикаций в известных социологических журналах, а также результатов исследований доверия, проведенных отечественными и зарубежными социологическими организациями, автор делает вывод о многообразии и разнородности подходов к изучению актуального социального феномена.

Ключевые слова: межличностное доверие, институциональное доверие, социальный институт, государственный институт, рейтинг

3 а последнее десятилетие масштабы изучения доверия социально-гуманитарными науками приобрели всеобъемлющий характер. Большой интерес исследователей к феномену доверия обусловлен его универсальностью и презентацией на всех уровнях социальной действительности.

Говоря об изучении доверия к основным социальным институтам общества, а также персонифицированного доверия к государственным руководителям, следует отметить, что большинство исследований проводятся не с целью всестороннего анализа социальной сущности и структуры доверия - на первый план выходят расчет индексов доверия, создание рейтингов социальных институтов и политических лидеров. Подобные исследования проводятся чаще не социологами-исследователями, а так называемыми полстерами. Однако деятельность ученых-социологов и полстеров отличается по своей цели и технологии ее реализации (см. табл. 1).

Сугубо прикладная, ориентированная на удовлетворение потребностей заказчика направленность таких исследований не всегда позволяет ответить на вопросы, что такое доверие и почему высокий уровень доверия позитивно влияет на общественное развитие. Каждый респондент понимает вопрос о доверии по-своему, о чем может свидетельствовать многообразие трактовок и классификаций социального явления даже в научной литературе.

Прежде чем приступать к проведению социологического исследования и измерению уровня доверия, необходимо определить, какой тип доверия подлежит измерению. Для этого целесообразно обозначить ряд подходов к его классификации. Выделяют следующие типообразующие основания: объект дове- 
Таблица 1

Различия в профессиональной деятельности социологов и полстеров

\begin{tabular}{|c|c|c|}
\hline & Социолог & Полстер \\
\hline $\begin{array}{l}\text { Объект } \\
\text { исследования }\end{array}$ & Социальное явление или процесс & $\begin{array}{l}\text { Группа населения или } \\
\text { население в целом }\end{array}$ \\
\hline $\begin{array}{l}\text { Цель } \\
\text { исследования }\end{array}$ & $\begin{array}{l}\text { Изучение общества, закономерностей } \\
\text { развития социальных процессов и } \\
\text { явлений в группах, организациях, } \\
\text { институтах и др. }\end{array}$ & $\begin{array}{l}\text { Изучение общественного } \\
\text { мнения }\end{array}$ \\
\hline $\begin{array}{l}\text { Методика } \\
\text { исследования }\end{array}$ & $\begin{array}{l}\text { Комплексное применение } \\
\text { общенаучных и социологических } \\
\text { методов }\end{array}$ & $\begin{array}{l}\text { Преимущественное } \\
\text { применение опросных } \\
\text { методов (чаще всего } \\
\text { интервьюирование) }\end{array}$ \\
\hline $\begin{array}{l}\text { Методика } \\
\text { анализа и } \\
\text { обработки } \\
\text { данных }\end{array}$ & $\begin{array}{l}\text { Использование различных методов } \\
\text { математико-статистического анализа } \\
\text { данных }\end{array}$ & $\begin{array}{l}\text { Преимущественное } \\
\text { использование одномерного } \\
\text { частотного распределения }\end{array}$ \\
\hline $\begin{array}{l}\text { Результат } \\
\text { исследования }\end{array}$ & $\begin{array}{l}\text { Ориентированность на получение } \\
\text { научного социологического знания }\end{array}$ & $\begin{array}{l}\text { Ориентированность на } \\
\text { удовлетворение потребностей } \\
\text { заказчика исследования }\end{array}$ \\
\hline
\end{tabular}

Таблица 2

\section{Классификация доверия}

\begin{tabular}{|c|c|c|c|}
\hline По объекту доверия & $\begin{array}{c}\text { По масштабу } \\
\text { распространенности } \\
\text { доверия }\end{array}$ & $\begin{array}{c}\text { По сферам } \\
\text { функционирования }\end{array}$ & $\begin{array}{c}\text { По социальным } \\
\text { границам }\end{array}$ \\
\hline $\begin{array}{l}\text { Персонификация } \\
\text { объекта }\end{array}$ & \multirow{6}{*}{$\begin{array}{l}\text { - международное } \\
\text { - внутригосударст- } \\
\text { венное } \\
\text { - региональное } \\
\text { - локальное }\end{array}$} & \multirow{6}{*}{$\begin{array}{l}\text { - организационное } \\
\text { - управленческое } \\
\text { - экономическое } \\
\text { - политическое } \\
\text { - нравственное } \\
\text { - психологическое } \\
\text { - правовое }\end{array}$} & \multirow{6}{*}{$\begin{array}{l}\text { - в вертикальных } \\
\text { границах } \\
\text { - в горизонтальных } \\
\text { границах }\end{array}$} \\
\hline $\begin{array}{l}\text { - персонифицирован- } \\
\text { ное } \\
\text { - не персонифици- } \\
\text { рованное }\end{array}$ & & & \\
\hline Тип объекта & & & \\
\hline $\begin{array}{l}\text { - доверие к себе } \\
\text { - доверие к другим } \\
\text { - доверие к миру }\end{array}$ & & & \\
\hline Масштаб объекта & & & \\
\hline $\begin{array}{l}\text { - межличностное } \\
\text { - групповое } \\
\text { - организационное } \\
\text { - институциональное } \\
\text { - общественное }\end{array}$ & & & \\
\hline
\end{tabular}

рия, масштаб распространенности доверия, сфера функционирования доверия, социальные границы доверия (см. табл. 2).

Наиболее релевантный подход к определению структуры доверия предполагает выделение трех его основных уровней.

1. Личностный, или психологический уровень. Доверие на этом уровне представ- 
лено как свойственная всем людям черта, обеспечивающая чувство онтологической безопасности. Психологический уровень доверия включает в себя доверие к самому себе и к своему социальному окружению. На личностном уровне доверию противопоставляется страх и чувство неопределенности.

2. Групповой, или социально-психологический уровень. Доверие здесь выражается прежде всего в сфере межличностных взаимодействий и социальных отношений между людьми в семье, трудовом или воинском коллективе и т.П.

3. Институциональный, или непосредственно социальный уровень. Этот уровень характеризует доверие к социальным организациям и институтам, а также внутри них, доверие к общественному устройству в целом [Барановский 2013: 136137].

При рассмотрении доверия как определенной социальной установки индивида данные уровни могут быть обозначены как когнитивный (институциональное доверие), поведенческий (групповое доверие) и эмоциональный (личностное доверие) [Зарубина, Носкова, Темницкий 2018б].

Анализ публикаций в ведущих научных социологических журналах подтверждает интерес академической науки к изучению доверия. Так, в журналах «Социс. Социологические исследования», «Социологический журнал» и «Власть» за последние 5 лет вышли 29 научных статей, посвященных социологическому осмыслению феномена доверия (см. рис. 1).

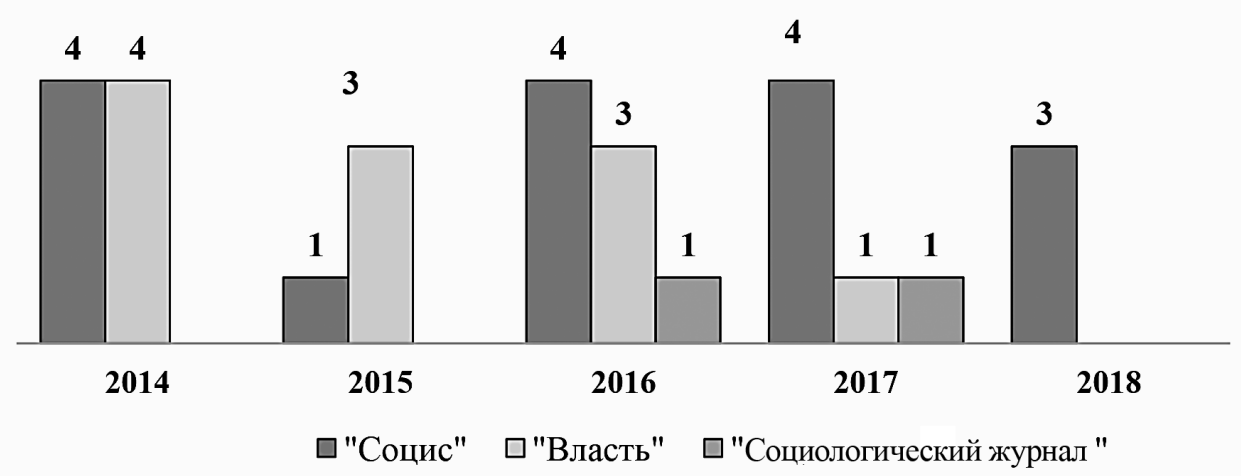

Рисунок 1. Статьи по тематике социологического изучения доверия в научных журналах (2014-2018 гг. $)^{1}$

Наибольшее число рассмотренных трудов посвящены изучению доверия в политической сфере. Самыми актуальными проблемами здесь являются оценка и прогнозирование электорального поведения граждан России, а также составление рейтингов доверия политическим институтам общества (президент, правительство, Федеральное собрание и др.) [Давыборец 2016; Данилов, Володина 2015; Кандель 2015; Козырева, Смирнов 2014; Реутов 2017; Реутов, Реутова 2015; Руденкин 2016; Смолина, Ширяева 2016].

\footnotetext{
1 См. [Алмакаева 2014; Базалеев 2016; Бобкова 2014; Вдовиченко 2018; Давыборец 2016; Данилов, Володина 2015; Зарубина 2018; Зарубина, Носкова, Темницкий 2018а; Кандель 2015; Китайцева, Кученкова 2014; Козырева, Смирнов 2014; Кошарная 2015; Кученкова 2016; Кученкова 2017; Мальцева 2014а; 2014б; Мукомель, Рыжова 2017; Реутов 2017; Реутов, Реутова 2015; Ромашкина, Давыденко 2014; Рубцова, Васильева 2016; Руденкин 2016; Рыжова 2016; 2017; Сасаки 2014; Смолина, Ширяева 2016; Староста, Бжезинский, Столбов 2017; Тарасова, Андрианова 2016; Трофимова 2017].
} 
Довольно часто доверие рассматривается как двухсоставный социальный феномен, включающий в себя межличностное доверие (доверие между людьми) и институциональное доверие (доверие социальным институтам). Сопоставляя эти два уровня, исследователи предпринимают попытку определить интегральный уровень общественного или социального доверия. Несколько реже доверие рассматривается на уровнях социальной организации или группы.

Такие отрасли научного знания, как этносоциология, социология образования и науки, социология семьи также рассматривают доверие в качестве предмета исследования [Зарубина 2018; Зарубина, Носкова, Темницкий 2018а; Мукомель, Рыжова 2017; Рыжова 2016; Сасаки 2014].

Тематическое распределение проанализированных публикаций позволяет говорить о распространенности феномена доверия во всех сферах общественной жизни и соответствующем отражении в современном научном знании (см. рис. 2).

\section{Политическая социология}

Исследования доверия социальным институтам и организациям

Теория и методология исследования доверия

Исследования межличностного доверия

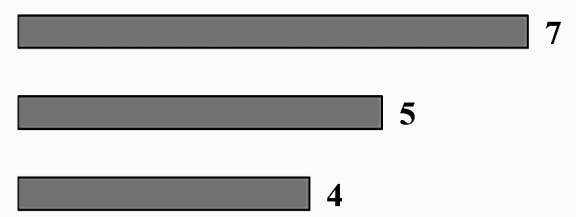

Этносоциология

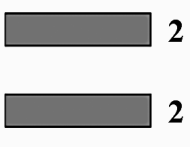

Социология образования и науки

2

Социология семьи

\section{2}

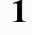

\section{Рисунок 2. Распределение статей по тематикам ${ }^{1}$}

На интерес к проблеме социологического изучения феномена доверия отреагировали и отечественные исследовательские агентства. Так, например, в ходе ежегодных международных социологических Грушинских конференций, проводившихся под эгидой Всероссийского центра изучения общественного мнения (далее - ВЦИОМ) и позиционировавшихся как «главное событие года в исследовательской индустрии», в период с 2013 по 2017 г. прозвучали 33 научных доклада, посвященных исследованию доверия в различных сферах общественной жизни.

Непосредственно прикладные исследования доверия, проводимые ВЦИОМом, посвящены в первую очередь построениям динамических рейтингов конкретных политических персоналий: В.В. Путина, С.К. Шойгу, С.В. Лаврова, Д.А. Медведева и др. Измерительная шкала в этом случае реализована открытым вопросом: «Все мы одним людям доверяем, другим - нет. А если говорить о политиках, кому Вы доверяете, а кому - не доверили бы решение важных государственных вопросов?»².

В то же время среди аналитических материалов ВЦИОМа можно встретить

\footnotetext{
1 См. там же.

2 Доверие политикам. Опрос ВЦИОМ от 27 января 2019 г. Доступ: https://wciom.ru/news/ratings/ doverie_politikam/ (проверено 06.02.2019).
} 
статьи и пресс-релизы, посвященные ранжированию государственных и общественных институтов по степени одобрения/неодобрения обществом их деятельности ${ }^{1}$. Интересно, что в комментариях специалистов-социологов категории «одобрение» и «доверие» рассматриваются как тождественные, что не всегда представляется возможным в свете раскрытия объективного состояния исследуемого феномена. По результатам ответов респондентов на закрытый вопрос: «Вы в целом одобряете или не одобряете деятельность государственного/ общественного института?» - делаются выводы об уровне доверия общества к этому институту ${ }^{2}$.

Несомненно, при оценке деятельности органов государственного управления необходимо рассматривать различные социальные характеристики. Возможно, в исследованиях ВЦИОМа одобрение выступает показателем не персонифицированного доверия тому или иному политическому деятелю, однако в таком случае различность методических подходов не позволяет вполне корректно сравнивать результаты измерения доверия и одобрения. В таблице этот тезис рассмотрен на примере сравнения рейтингов одобрения деятельности президента РФ и доверия к нему (см. табл. 3).

Таблица 3

Одобрение деятельности и доверие президенту РФ (по данным ВЦИОМа) 3

\begin{tabular}{|c|c|c|c|}
\hline Вопрос & Одобрение, \% & Неодобрение, \% & $\begin{array}{c}\text { Индекс } \\
\text { одобрения }\end{array}$ \\
\hline $\begin{array}{l}\text { Вы в целом одобряете или не одобряете } \\
\text { деятельность Президента РФ?* }\end{array}$ & 61 & 30,1 & 31 \\
\hline \multirow{2}{*}{$\begin{array}{l}\text { Все мы одним людям доверяем, другим } \\
\text { - нет. А если говорить о политиках, } \\
\text { кому Вы доверяете, а кому - не } \\
\text { доверили бы решение важных } \\
\text { государственных вопросов?** }\end{array}$} & Доверие, \% & Недоверие, \% & Индекс доверия \\
\hline & 32,2 & 8,1 & 24 \\
\hline
\end{tabular}

* Закрытый вопрос, один ответ.

** Открытый вопрос, любое число ответов.

Несколько иной подход к изучению доверия представлен в исследованиях, проводимых Фондом «Общественное мнение» (далее - ФОМ). Так, например, доверие президенту РФ выступает одним из основных показателей в ходе социологической оценки отношения граждан к его деятельности. Респондентам предлагается ответить на два закрытых вопроса: «Скажите, пожалуйста, вы доверяете или не доверяете В. Путину?» и «За последний месяц вы стали больше или меньше доверять В. Путину?» В своих опросах специалисты ФОМа не разделяют персонифицированного политика и не персонифицированный государственный институт ${ }^{4}$.

Большой интерес представляют системные социологические исследования ФОМа, связанные с определением атмосферы межличностного доверия в

\footnotetext{
${ }^{1}$ Известия: Вотум доверия: россияне по-прежнему одобряют деятельность армии и РПЦ. Аналитика экспертов ВЦИОМ от 20 ноября 2018 г. Доступ: https://wciom.ru/index.php?id=238\&uid=9437 (проверено 06.02.2019).

2 Деятельность государственных институтов. Опрос ВЦИОМ от 27 января 2019 г. Доступ: https:// wciom.ru/news/ratings/odobrenie_deyatelnosti_gosudarstvennyx_institutov/ (проверено 06.02.2019).

3 Там же; Доверие политикам. Опрос ВЦИОМ от 27 января 2019 г. Доступ: https://wciom.ru/news/ ratings/doverie_politikam/ (проверено 06.02.2019).

4 В. Путин: рейтинг, отношение, оценки работы. Индикаторы отношения к главе государства. Опрос ФОМ от 20 января 2019 г. Доступ: https://fom.ru/posts/10946 (проверено 06.02.2019).
} 
современном российском обществе. В основе этих исследований лежит измерение уровней доверия населения большинству людей и своему социальному окружению ${ }^{1}$.

Прикладные исследования доверия также проводятся и зарубежными социологическими организациями. Наиболее масштабным из них можно считать ежегодный мониторинг уровня доверия в разных государствах, проводимый $P R$-агентством Edelman. Исследование проводится в 28 странах мира и может быть интересно социологам как пример комплексного структурного подхода к анализу феномена доверия.

Структура доверия, по версии специалистов Edelman, трехсоставная и включает в себя доверие общественно значимым социальным институтам (социальное доверие), доверие промышленным корпорациям и брендам (экономическое доверие) и доверие конкретным индивидам - как государственным чиновникам, так и людям, окружающим нас в повседневных практиках взаимодействия (социально-психологическое и межличностное доверие).

В 2018 г. доклад Edelman Trust Barometer вышел под заголовком «Битва за доверие» ${ }^{2}$. Центральной темой доклада является резкое падение уровня доверия в США и выявление его причин. Так, по данным агентства, зафиксировано рекордное снижение показателей доверия в американском обществе за всю историю наблюдений. Уровень доверия, по мнению населения, опустился на 9 пунктов (с 52 до 43), а по мнению экспертов - упал на 23 пункта (с 68 до 45), что сделало его самым низким среди 28 участвовавших в исследовании стран ${ }^{3}$.

Крах доверия в США обусловлен отсутствием уверенности в деятельности правительства, недоверием институтам бизнеса, средствам массовой информации и неправительственным организациям.

По данным исследования, недоверие к СМИ является в последнее время общемировой тенденцией. Так, около $70 \%$ респондентов беспокоятся о том, что поддельные новости и ложная информация в СМИ используются в качестве «информационного оружия», воздействие которого направлено на дестабилизацию политической и социальной обстановки в их государствах ${ }^{4}$.

Следует отметить, что в исследованиях Edelman Trust Barometer, несмотря на их детальную методологическую проработку, не делается социокультурных различий между странами. Например, Россия стабильно занимает низкие места рейтинга в связи с недоверием неправительственным организациям. В исследовании не учитывается, что этот институт не столь значим для населения нашей страны, как для представителей зарубежных стран.

Анализ современного опыта социологического исследования доверия показывает, насколько многогранным и сложносоставным предстает этот феномен для исследователей. Гуманитарным наукам еще предстоит выработать единые подходы к классификации и систематизации доверия как социального явления. Особенно актуальным в условиях динамично трансформирующегося общественного устройства представляется осмысление доверия как важнейшего элемента системы социального и, в частности, государственного управления.

\footnotetext{
1 Доверие как фактор общественной жизни. Интервью с Л.А. Паутовой от 06 июня 2017 г. Доступ: http://2035.media/2017/06/06/pautova-interview/ (проверено 06.02.2019).

2 Edelman TRUST BAROMETER. Опрос Edelman за 2018 г. Доступ: https://www.edelman.com/ research/2018-edelman-trust-barometer (проверено 06.02.2019).

3 Индекс доверия рассчитывается в пределах от 1 до 100. В зависимости от полученного индекса страны подразделяются на «доверяющие» (60-100 пунктов), «нейтральные» (50-59 пунктов) и «не доверяющие» (1-49 пунктов).

4 Edelman TRUST BAROMETER. Опрос Edelman за 2018 г. Доступ: https://www.edelman.com/ research/2018-edelman-trust-barometer (проверено 06.02.2019).
} 


\section{Список литературы}

Алмакаева А.М. 2014. Измерение генерализованного (обобщенного) доверия в кросскультурных исследованиях. - Социс. Социологические исследования. № 11. C. 32-43.

Базалеев О.А. 2016. Кризис доверия в «несостоявшемся обществе». Случай социальной стагнации. - Социс. Социологические исследования. № 3. С. 177-187.

Барановский М.В. 2013. Феномен доверия в современных социологических исследованиях. - Власть. Т. 21. № 6. С. 134-137.

Бобкова Е.М. 2014. Доверие как фактор целостности общества. - Социс. Социологические исследования. № 10. С. 70-75.

Вдовиченко Л.Н. 2018. Международная конференция по доверию в Японии. - Социс. Социологические исследования. № 6. С. 152-154.

Давыборец Е.Н. 2016. «Феномен» доверия президенту России. - Социс. Социологические исследования. № 11. С. 107-113.

Данилов С.А., Володина С.В. 2015. Электоральное доверие: концептуальные профили и риск-факторы. - Власть. Т. 23. № 8. С. 67-73.

Зарубина Н.Н. 2018. Доверие к науке в современной России в контекстах множественности форм знания. - Социс. Социологические исследования. № 5. C. $111-120$.

Зарубина Н.Н., Носкова А.В., Темницкий А.Л. 2018а. Доверие к социальной науке в России как исследовательская проблема. - Социс. Социологические исследования. № 7. С. 105-114.

Зарубина Н.Н., Носкова А.В., Темницкий С.Л. 2018б. Доверие к социальным наукам: взгляд университетской молодежи. - Вестник Томского государственного университета. Философия. Социология. Политология. № 41. С. 114-123.

Кандель П.Е. 2015. Подозрительная кардиограмма, или кризис доверия (выборы в Юго-Восточной Европе). - Власть. Т. 23. № 3. С. 161-166.

Китайцева О.В., Кученкова А.В. 2014. Доверие и индивидуализм в мировоззрении современной молодежи восточноевропейских стран. - Социс. Социологические исследования. № 12. С. 97-104.

Козырева П.М., Смирнов А.И. 2014. О границах политического доверия. Власть. Т. 22. № 5. С. 5-10.

Кошарная Г.Б. 2015. Институциональное и межличностное доверие в консолидации российского общества. - Власть. Т. 23. № 9. С. 125-129.

Кученкова А.В. 2016. Межличностное доверие в российском обществе. Социс. Социологические исследования. № 1. С. 26-36.

Кученкова А.В. 2017. Российская интеллигенция и институты: доверие или отчуждение? - Социс. Социологические исследования. № 10. С. 113-121.

Мальцева А.П. 2014а. Полноценное доверие: понятие, проблема, методика формирования. - Власть. Т. 22. № 7. С. 115-119.

Мальцева А.П. 2014б. Социальное доверие в современной России: состояние, причины кризиса, условия «излечения». - Власть. Т. 22. № 11. С. 49-52.

Мукомель В.И., Рыжова С.В. 2017. Доверие и недоверие в межнациональных отношениях. - Социс. Социологические исследования. № 1. С. 37-46.

Реутов Е.В. 2017. Институционализация недоверия в легитимации социоструктурных взаимодействий в местных сообществах. - Власть. Т. 25. № 7. C. $85-91$

Реутов Е.В., Реутова М.Н. 2015. Недоверие в установках и практиках населения. - Социс. Социологические исследования. № 6. С. 126-132.

Ромашкина Г.Ф., Давыденко В.А. 2014. Социокультурные основания институционального доверия. - Власть. Т. 22. № 12. С. 122-130.

Рубцова М.В., Васильева Е.А. 2016. «Доверие»: концептуализация и операци- 
онализация понятия в корпусной лингвистике. - Социс. Социологические исследования. № 1. С. 58-65.

Руденкин Д.В. 2016. Экономический кризис как фактор снижения доверия граждан к российской исполнительной власти: миф или реальность. - Власть. T. 24. № 10. C. 108-115.

Рыжова С.В. 2016. Доверие и этническая толерантность в условиях социальных перемен. - Социологический жсурнал. Т. 22. № 1. С. 72-94.

Рыжова С.В. 2017. Религиозность в контексте культуры доверия. Социологический жмурнал. Т. 23. № 3. С. 45-63.

Сасаки М. 2014. Семейная социализация и опыт предательства: кросснациональный анализ доверия. - Социс. Социологические исследования. № 2. С. 10-24.

Смолина Е.Г., Ширяева В.А. 2016. Доверие как социальная технология в сети отношений власти и общества. - Власть. Т. 24. № 4. С. 143-149.

Староста П.Ю., Бжезинский К.В., Столбов В.П. 2017. Структура социального доверия в постиндустриальных городах Центральной и Восточной Европы. Социс. Социологические исследования. № 12. С. 79-88.

Тарасова А.Н., Андрианова Е.В. 2016. Инновационная активность и внутриорганизационное доверие: проблема взаимосвязи. - Власть. Т. 24. № 11. С. 130-137.

Трофимова И.Н. 2017. Структура и динамика институционального доверия в современном российском обществе. - Социс. Социологические исследования. № 5. C. $68-75$.

\title{
MODERN PRACTICES OF SOCIOLOGICAL STUDY OF THE PHENOMENON OF TRUST
}

\begin{abstract}
The paper provides an overview of the main modern practices of the sociological study of trust. The author suggests various grounds to classify trust as a social phenomenon. Based on the analysis of the subject and content of scientific publications in well-known sociological journals, as well as taking into consideration results of trust studies conducted by domestic and foreign sociological organizations, this study concludes that there is a diversity and heterogeneity of approaches to the study of this universal social phenomenon.

Currently, most studies do not intend to analyze the social nature and structure of trust comprehensively. First, a researcher of trust is to determine what type of trust is to be measured. In turn, the most relevant approach to determine the structure of trust involves the allocation of its three main levels: personal (psychological), group (socio-psychological) and institutional (social). Moreover, considering trust as a specific social setting of the individual one can designate these levels as emotional, behavioral, and cognitive.

An analysis of contemporary experience in a sociological study of trust shows how versatile and complex this phenomenon appears to researchers. The humanities have not develop yet common approaches to the classification and systematization of trust as a social phenomenon.
\end{abstract}

Keywords: interpersonal trust, institutional trust, social institution, state institution, rating 